\title{
Identification of the quality of urban life assessment aspects in residential neighbourhoods in Doha
}

\author{
R. Qawasmeh \\ Department of Architecture and Urban Planning, \\ Qatar University, Qatar
}

\begin{abstract}
This study presents the development of an assessment tool model that evaluates the quality of urban life (QOUL) in residential neighbourhoods in Doha, Qatar, based on a substantial literature review of the QOUL concept. The tool aims to assess the built environment qualities and the level of satisfaction of the residents based on their real interaction and relationship with their living built environment. The study introduces aspects and criteria that should be considered for improving the physical qualities of the residential neighbourhoods and contributes towards enhancing its social and perceptual dimensions. This assessment tool follows a framework to direct its investigation, which consists of two dimensions. The first stage assesses and tests the urban quality (UQ) in the neighbourhood, primarily to evaluate the built environment attributes and examines human behaviour, interaction and urban activity. The second stage assesses and determines the level of residential satisfaction and attachment (RS) in the neighbourhoods by users in order to determine an effective appraisal of users with their built environment elements. The conclusion provides an understanding of the significant physical, social, and perceptual aspects in residential areas in Doha to assist urban designers in specifying the major needs of the residences, as well as to support the improvement of Doha's neighbourhood legislation that corresponds to Doha's climate, culture and social situation. Another important aspect was to improve the assessment tool with specific aspects and criteria that can be used in future studies and future residential development.
\end{abstract}

Keywords: quality of urban life (QOUL), quality of life, residential satisfaction, urban qualities, assessment tool. 


\section{Introduction}

\subsection{Research overview and problem}

This research study focuses on assessing the quality of urban life in residential neighbourhoods in Doha by developing an assessment tool model for residential qualities. The study measures and analyses existing aspects and features in Doha's residential neighbourhoods with the aim of identifying the distinct and particular nature of urbanism in Doha.

Qatar has recently become an attractive living and working destination for people from a variety of different backgrounds and cultures. This has resulted in a population with diverse needs. In addition, Qatar is currently undergoing a process of massive urban and infrastructural development, which is a result of unprecedented rapid urban and economic growth (fig. 1).

Because Doha is located in an extremely hot and dry desert littoral region in the Arabian Gulf, it has specific climate and environmental conditions that need to be taken into consideration to enhance the quality of the built environment of its neighbourhoods to be more liveable, attractive, user-friendly, and walkable. Currently, urban settings are being developed without consideration of the quality of urban life. Most developers of residential neighbourhoods only plan for the accommodation aspect, i.e. housing demand, without taking into consideration diverse habitat needs and the liveability perceptions of the residents. As a result, the social and perceptual dimension is generally ignored.

Enhancing the built environment and its social and perceptual dimensions by improving the quality of the physical attributes of neighbourhoods according to user specifications should help satisfy inhabitant and user needs for a more liveable and enjoyable built environment.

The present study identifies factors that should exist in neighbourhoods to enhance the relationships between inhabitants and their residential environment for the purpose of providing suggestions for neighbourhood improvement from community and user perspectives according to these selected factors. This is accomplished through the development of an assessment tool based on previous studies assessing Quality of Urban Life (QOUL) in residential neighbourhoods, which was then used to study the qualities of specific physical and social aspects of neighbourhoods in Doha. For later research this will be followed by testing the assessment tool on existing real case studies, with qualitative methods as a confirmation of its efficiency and help with its development and design (fig. 2). This assessment tool can be used by governmental institutions and urban planners as a reference guide for improving residential areas. In addition, the conclusions of this study can be used as a reference for future researchers in the field supporting future development of qualitative methods to enhance the built environment of the residential areas in Doha and other contexts that matches the real and existing needs of residential users and inhabitants.

The quality of life in a residential environment is determined by objective values that affect a given group of people that share a common physical, social and environmental perception of their living conditions. This is in addition to 
subjective values, which are identified by assessing and studying the users' and residents' satisfaction with their quality of residential life. People experience their neighbourhood in different ways. This experience is a result of their direct interaction with the physical features and elements of their living environment. This experience is translated into different behavioural responses and relative bonds that reflect their feelings and their level of satisfaction with their living environment; hence it is evident that a neighbourhood necessitates direct interaction with people for their daily needs. For a neighbourhood to be considered desirable and liveable, it should fulfil all QOUL dimensions and thus provide a high level of satisfaction and accessibility to all of its physical elements for users. Satisfying these requirements will affect the social and physical interaction of users and residents. With this in mind, designing a neighbourhood that provides for all the main social and perceptual needs of users will enhance the QOUL level and foster resident satisfaction. Developing the assessment tool focused on selecting the major physical elements, aspects and dimensions that were consisted important in to QOUL (figs 3 and 4).
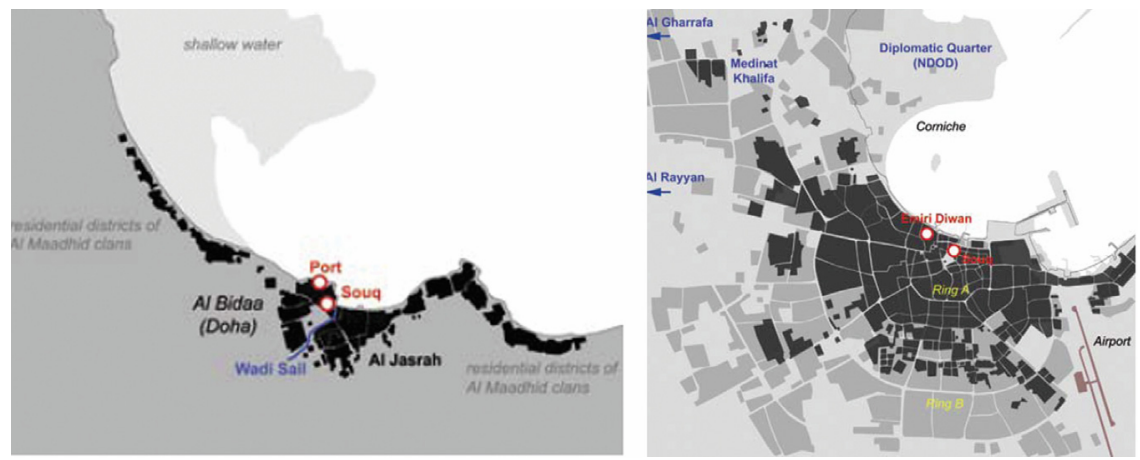

Figure 1: Urban expansion of Qatar pre-oil period (1947 to 2007) (Salama et al. [1]).

The research procedure for this study focused on investigating human activity (behaviour) in residential neighbourhoods in Doha. The main purposes are to identify the main aspects that affect the QOUL in Doha's neighbourhoods and to develop the QOUL assessment tool by answering: what are the main factors that shape the notion of resident satisfaction and place attachment in Doha neighbourhoods, and what are the main elements that ought to be considered while designing residential neighbourhoods in Doha?

\section{Literature review}

The literature review for this study focused on defining QOUL and the quality of the residential neighbourhood and identifying the main quality dimensions. These, in turn, helped structure the study framework and underpinned the development of the assessment tool criteria. Investigating living standards and quality of living 
spaces and places is an important field of research that requires a number of analytical research strategies. While such studies are quite common in Europe, Australia and North America, very few similar studies on QOUL and residential satisfaction have been undertaken in Middle Eastern countries, including Qatar.

Of particular interest to this study are previous studies that investigated the significance of quality of life as it relates to residential satisfaction. In the introduction to the comprehensive text on wellbeing, Kahneman et al., as quoted in Marans [2] presented an overview of the literature that addressed global evaluations of quality of life. They stated that the quality of life experience is embedded in the cultural and social context of both the subject and the evaluator. Mulligan et al., as discussed in Marans and Stimson [3] defined QOL as "...the satisfaction that a person receives from surrounding human and physical conditions, conditions that are scale-dependent and can affect the behaviour of individual people or groups."

Investigating QOUL includes examination of the relationships between the characteristics of living places and the people that live there. In addition, studying QOUL involves examining the patterns of intra-urban mobility as mentioned by Keeble and Lev, in Marans and Stimson [3]. According to Szalai in Kamp et al. [4], the quality of life refers to "...the degree of excellence or satisfactory character of life. A person's existential state, well-being, satisfaction with life is determined on the one hand by exogenous (objective) facts and factors of his life and on the other hand by the endogenous (subjective) perception and assessment he has of these facts and factors, of life of himself." It is therefore clear that quality of life depends, to a large extent, on an individual's well-being and perceptions of wellbeing.

The investigation of QOUL can be achieved by using two approaches advocated by Andelman et al. in Marans and Stimson [3]. The first approach is the objective approach, which is most typically confined to the analysis at different geographic special scales. This is done by testing the physical and functional dimensions of the neighbourhood elements. The second approach is the subjective approach, designed to collect data at individual levels using social assessment, focusing on the people's behaviours. This study focused on the subjective side to formulate the assessment tool criteria by focusing on the users' needs, desires and opinions and by examining and evaluating the relationship between the characteristics of the urban environments and the relationship to user and resident behaviours and interaction. As a result, it is a qualitative research. The objective attributes were not ignored, however, the assessment tool investigate and assess some of the physical features in the neighbourhoods, which are includes in the assessment tool; in regards to how people are using these features and interact with it.

According to Hester [5] a neighbourhood space is "that public outdoor territory close to home, which because of the residents' collective responsibility, familiar association, and frequent shared use, is considered to be their own". It is therefore imperative for an acceptable quality of life that people feel comfortable with the neighbourhood they live in and interact with. People need to feel ownership of place and space. When they do, they take more of an interest in it and interact with 
it on a more personalised level. Romice in Aiello et al. [6] notes that a community's personal and interactive experience can be a fundamental starting point in the process of creating sustainable environments and neighbourhoods for users. Accordingly, neighbourhood improvement should be based on the analysis of not only how residents use, interact, and experience their residential environment, but also on what makes them satisfied with it. Lee in Amerigo and Juan [7] suggests that the urban neighbourhood should be more succinctly defined as a socio-spatial schema, that is, the unification of both the social and physical components of a neighbourhood. Every user defines a neighbourhood according to his own life experiences and standards. Lynch [8] calls this 'imageability': "...every user and resident translates these elements due to his life experience in the neighbourhood and his own understanding and his own uses." A neighbourhood should contain different public spaces with different facilities for different users. These should be designed for and should provide for various inhabitant activities, needs and desires. In addition, a good neighbourhood should include empty spaces or parks between housing units and residences that children can use as play areas so that the community experiences liveability of the built environment on the quality of facilities, infrastructure and housing that it provides. Aiello et al. [6], based on Canter (1977), evaluated several residential neighbourhoods in Rome by examining the relationships between the physical attributes of the environment, the cognitive perceptions and the affective appraisals of residents, and the activities the activities they carry out. According to Moustafa [9], a local community is characterized by three major elements: a specific set of needs, wants, and interests shared by members; specific appropriate or desired behavioural mechanisms through which these needs, wants, and interests are thought to be fulfilled or pursued; and a spatial or geographical base at a specific scale of the residential environment. The development of the assessment tool was based on understanding the previous literature review aspects related to QOUL, which focused on investigating the residents' needs by observing, evaluating and analysing their actions, interactions and behaviour with their existing built environment.

\section{Research framework and assessment tool development}

The framework used in the study focuses on assessing two dimensions of QOUL: urban quality and residential satisfaction. At the same time the assessment tool aspects and criteria follow the framework trajectory in the assessment procedure. This process involved two stages. The first stage assesses physical and social dimensions (fig. 2), which are grouped under Urban Quality (UQ) in the neighbourhood, primarily to evaluate the built environment's physical attributes with regard to their functional and spatial aspects and to examine human behaviour, interaction and urban activity, focusing on the qualitative values of these aspects. For example, Canter in Aiello et al. [6] mentioned that the findings of such an investigation will support the premise that resident and residential satisfaction is actually a multidimensional construct wherein user perceptions of different specific aspects of a place, such as spatial features, human features, and 
functional features, must be considered. It is important to note that the physical dimension of a built environment (i.e. inhabitant use) impacts the social dimension (i.e. user behaviour), while the perceptual dimension is a result of social dimension interaction with the physical attributes of the neighbourhood built environment. Oktay and Marans [10] suggested that to make a neighbourhood an appropriate place to live and to raise children, with easy availability of things to do there, such facilities as parks and play areas should be provided in accessible locations. Smith et al. [11] also developed specific criteria to measure the physical qualities of the neighbourhood environment. These included livability, character, connection, personal freedom and diversity. In addition to these neighbourhood features and elements, Oktay and Marans [10] examined other physical attributes such as cleanness, noise level and traffic intensity.

The social dimension refers to aspects of human behavior and the social needs that should be available in a neighborhood. This part of the study explored the main factors and criteria that are related to how the residents behave and interact with their built environment. Marans in Richman [12] introduced a categorization for these needs that the assessment took into consideration: (1) the need to escape from the physical stresses of the environment, (2) the need to experience nature (vegetation, greenery), (3) the need for privacy, (4) the need for security and safety for self and family (safety), (5) affiliation and belonging (6) social recognition and status, (7) physical exercise and physical activity services, and (8) tension release. The main methods that will be used in testing the assessment tool criteria for this dimension in future are analytical mapping based on walk-through assessments and field observations (fig. 2).

The second stage assessed and determined the third dimension (users' perceptual dimension), which is classified under the level of residential satisfaction and residential attachment in the neighborhoods by users in order to determine an effective appraisal of users with their built environment elements in addition to establishing a basic understanding of residential neighborhood satisfaction and residential attachment. It was used to analyze the importance of the residential neighborhood with regard to user perceptions and perspectives. The main method that will be used in testing the assessment tool criteria for this dimension in future is face-to-face interviews to obtain residents' views of their respective neighborhood (fig. 2).

The investigation used the assessment tool, which is based on the three main dimensions: physical, social and perceptual. Mainly it assessed three selected elements from neighborhoods, which are residential houses layout, services facilities and circulation networks (figs 3 and 4). The three dimensions' investigation helps in assessing and measuring the quality of urban life in respect to selected neighborhood elements. The three dimensions covered are as follows:

- The first criterion involved investigating physical qualities, including the functional and spatial characteristics for housing, buildings, services, and circulation elements of the neighborhoods. These were categorized according to diversity, accessibility, location, availability, architectural features and landscape features (fig. 3). 
- The second dimension, the social dimension, examined human behavior and interaction with the physical elements of the neighborhood. In addition, the study carefully did on-site observation of the availability or lack of the specific elements requisite to increase human behavior and interaction; these were noted, measured and assessed (fig. 3).

- The third dimension, the perceptual dimension, was investigated to determine the concept of QOUL with regard to user satisfaction with the built environment, including residential satisfaction, attachment to their living area, enjoyment, sense of belonging and sense of place. Their perceptions of neighborhood attractiveness or unattractiveness were also queried and noted (fig. 4).

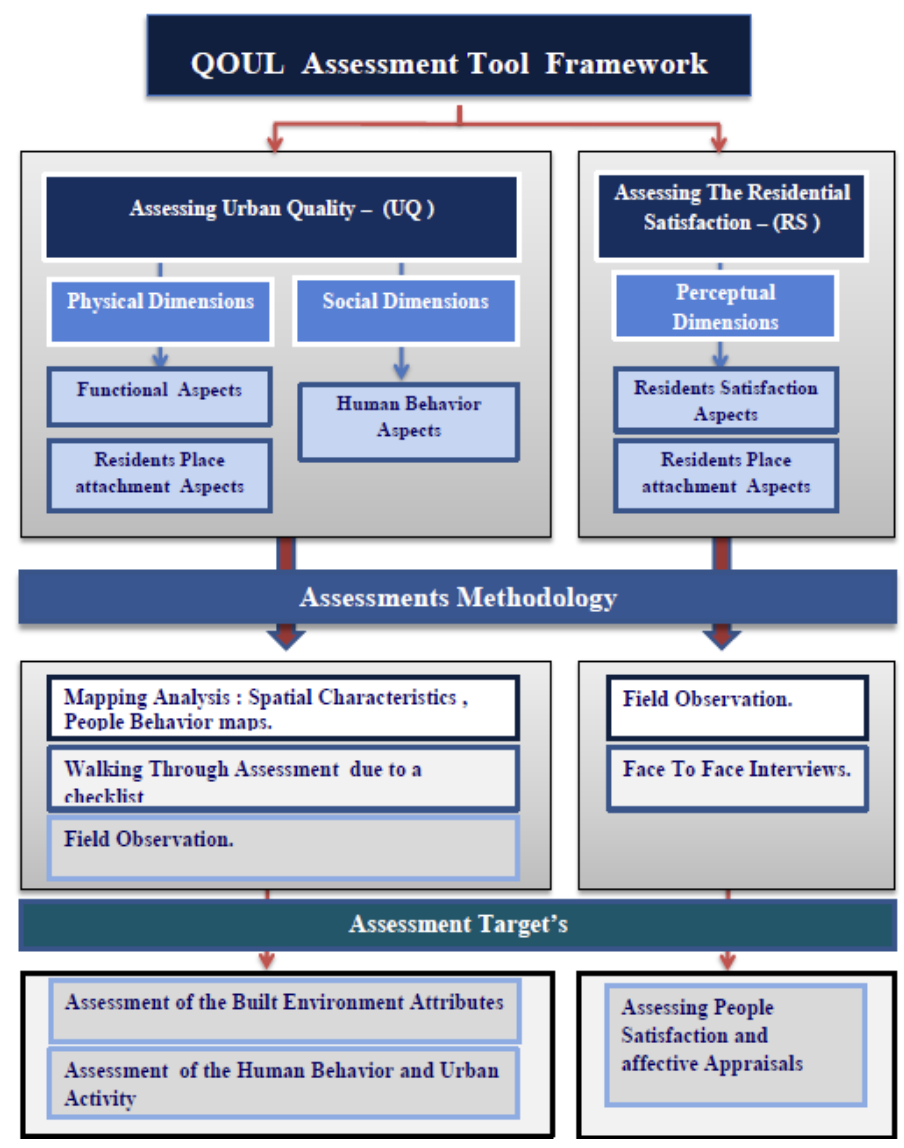

Figure 2: QOUL Adaptive research framework diagram (author, 2013). 


\begin{tabular}{|c|c|c|c|c|c|}
\hline \multirow{2}{*}{\multicolumn{3}{|c|}{$\begin{array}{l}\text { Urban Quality } \\
\text { Assessments } \\
\text { Aspects -(UQ) }\end{array}$}} & \multicolumn{3}{|c|}{ Neighborhood Elements } \\
\hline & & & Residential Building & Services Building & Circulation \\
\hline \multirow{4}{*}{ 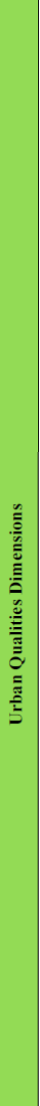 } & \multirow{4}{*}{ 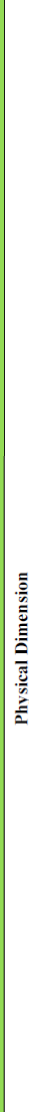 } & 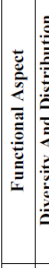 & $\begin{array}{l}\text { Typology: } \\
\text {-Private Villas. } \\
\text {-Residential apartment. } \\
\text {-Residential Compounds. }\end{array}$ & $\begin{array}{l}\text { Availability of the services: } \\
\text {-Accessibility \& distribution } \\
\text { of Commercial services. } \\
\text {-Transport service. } \\
\text {-Worship services. } \\
\text {-Educational services. } \\
\text {-Recreational services \&Open } \\
\text { spaces. } \\
\text {-Activity services. }\end{array}$ & $\begin{array}{l}\text {-Types of parking facilities } \\
\text {-Pedestrian sidewalks and } \\
\text { routes. } \\
\text {-Vehicular movement. } \\
\text {-Streets. }\end{array}$ \\
\hline & & \multirow{3}{*}{ 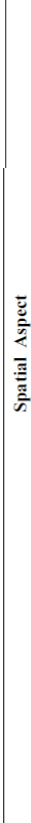 } & $\begin{array}{l}\text {-Building type \&height. } \\
\text {-Building material quality. } \\
\text {-Setbacks -Building status. } \\
\text {-Façade maintenance. } \\
\text {-Cleanliness. }\end{array}$ & $\begin{array}{l}\text {-Building type \&height. } \\
\text {-Building material quality . } \\
\text {-Setbacks -Building status. } \\
\text {-Architectural style. } \\
\text {-Façade maintenance. } \\
\text {-Cleanliness. }\end{array}$ & $\begin{array}{l}\text {-Architectural status. } \\
\text {-Building material quality. } \\
\text {-Building Density. } \\
\text {-Setbacks. }\end{array}$ \\
\hline & & & $\begin{array}{l}\text {-Main access points. } \\
\text {-Bikability. } \\
\text {-Adequate \& sufficient } \\
\text { parking space. } \\
\text {-Impeded/unimpeded } \\
\text { sidewalks for pedestrian } \\
\text { movement. } \\
\text {-Adaptations\& accessibility } \\
\text { for handicapped residents. } \\
\text {-Street width Adequate } \\
\text { shade \& Appropriate } \\
\text { lighting. } \\
\text {-Traffic density. }\end{array}$ & $\begin{array}{l}\text {-Main access points. } \\
\text {-Bikability \& sufficient } \\
\text {-Adequate \& } \\
\text { parking space. } \\
\text {-Impeded/unimpeded } \\
\text { sidewalks for pedestrian } \\
\text { movement . } \\
\text {-Adaptations \& accessibility } \\
\text { for handicapped residents. } \\
\text {-Street width Adequate shade } \\
\text { \& Appropriate lighting. } \\
\text {-Traffic density. }\end{array}$ & $\begin{array}{l}\text {-Main access points. } \\
\text {-Bikability. } \\
\text {-Adequate \& sufficient } \\
\text { parking space. } \\
\text {-Impeded/unimpeded } \\
\text { sidewalks for pedestrian } \\
\text { movement. } \\
\text {-Adaptations \& accessibility } \\
\text { for handicapped residents. } \\
\text {-Street width Adequate shade } \\
\text { \& Appropriate lighting } \text {. } \\
\text {-Traffic density. }\end{array}$ \\
\hline & & & $\begin{array}{l}\text {-Private green areas } \\
\text { Greenscape on or near } \\
\text { sidewalks. } \\
\text { Sufficient green areas } \\
\text { within walkable distances } \\
\text { Condition/Status of existing } \\
\text { green spaces. } \\
\text { Walkability/accessibility of } \\
\text { green spaces. }\end{array}$ & $\begin{array}{l}\text {-Existence/non-existence of } \\
\text { green spaces } \\
\text {-Greenscape on or near } \\
\text { sidewalks } \\
\text {-Sufficient green areas within } \\
\text { walkable distances } \\
\text {-Condition/Status of existing } \\
\text { green spaces } \\
\text {-Walkability/accessibility of } \\
\text { green spaces }\end{array}$ & $\begin{array}{l}\text {-Greenscape on sidewalks } \\
\text {-Natural shade from } \\
\text { greenscape. } \\
\text {-Interactive environment. }\end{array}$ \\
\hline \multirow{2}{*}{ 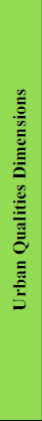 } & \multirow[t]{2}{*}{ 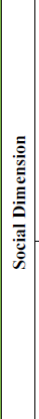 } & 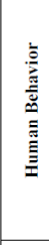 & $\begin{array}{l}\text {-Privacy. } \\
\text {-Security. } \\
\text {-Social Interaction. }\end{array}$ & $\begin{array}{l}\text {-Safety . } \\
\text {-Walkability \& Bikability. } \\
\text {-Social Interaction. } \\
\text {-Greenscape/green spaces. } \\
\text {-Shading. } \\
\text {-Socioeconomic activities. } \\
\text {-Types of activity. } \\
\text {-Children's safety \& activities. } \\
\text {-Attractive environment. }\end{array}$ & $\begin{array}{l}\text {-Safety . } \\
\text {-Walkability \& Bikability. } \\
\text {-Social Interaction. } \\
\text {-Greenscape/green spaces. } \\
\text {-Shading. } \\
\text {-Socioeconomic activities. } \\
\text {-Types of activity. } \\
\text {-Children's safety \& activities. } \\
\text {-Attractive environment. }\end{array}$ \\
\hline & & 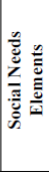 & $\begin{array}{l}\text {-Lighting elements } \\
\text {-Shading elements } \\
\text {-Open spaces } \\
\text {-Safe main entrances }\end{array}$ & $\begin{array}{l}\text {-Lighting elements } \\
\text {-Shading elements. } \\
\text {-Condition of } \\
\text { sidewalks/pedestrian areas } \\
\text {-Bike paths } \\
\text {-Greenscape and trees }\end{array}$ & $\begin{array}{l}\text {-Lighting elements } \\
\text {-Shading elements. } \\
\text {-Condition of } \\
\text { sidewalks/pedestrian areas } \\
\text {-Bike paths } \\
\text {-Greenscape and trees }\end{array}$ \\
\hline
\end{tabular}

Figure 3: Assessment tool (urban quality dimension's) criteria: Urban quality assessment aspects (author, 2013). 


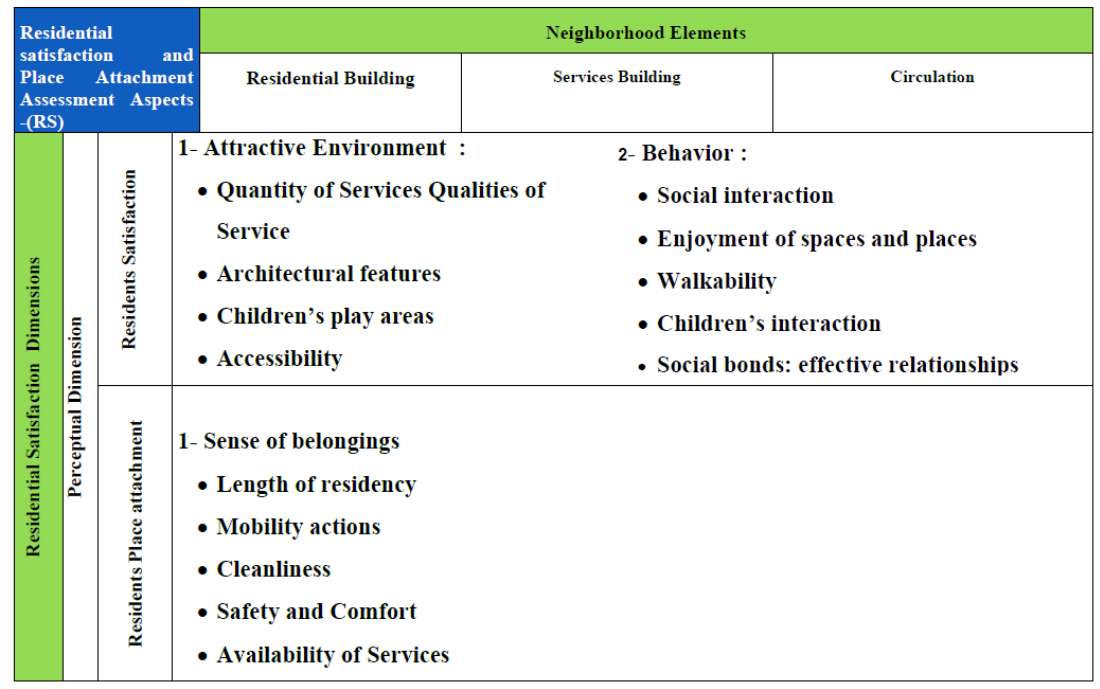

Figure 4: Assessment tool (perceptual aspect) criteria, residential satisfaction and place attachment assessment aspect (author, 2013).

\section{Discussion and conclusions}

The assessment tool involved qualifying the physical services by understanding the interaction of the residents and their perceptions of the neighbourhood (liveable, walkable built environment with visual appeal). This assessment tool could be used by city planners and policy makers to design and develop basic quality standards underpinned by specific criteria to refer to when planning future residential neighbourhoods, as well as provide recommendations and standards to further develop the assessment tool for future development. The assessment tool determined what facilities and services residents actually use and need. The assessment tool has specific criteria and aspects that target the improvement of the physical elements, which raise the user's satisfaction and attachment shown by their social behaviours from the user's point of view. Walkability, bikeability, and socializing create a major and important issue in Doha's neighbourhood, and residents demand these increase. According to Jacobs and Whyte in Carmona et al. [13], criteria for appropriate and functional physical elements should include the following: "...good streets, sidewalks, parks, and other public spaces, which bring out the best in human nature and provide the setting for civil and courteous society. Everything will be fine if we can just get the design right...." 


\subsection{Conclusions and challenges for the assessment tool}

An analysis of the literature review provided background data and referents for designing the research framework and appropriate assessment tool. This helped the researcher prepare a study that investigated and analysed the dynamic interaction and conceptual validity between the resident and his/her residential environment; this included several processes, such as cognitive, affective and behavioural, all of which take place in such interactions.

One problem noted by the researcher is that the definition of the residential environment (as mentioned in studies in the literature review) was rather unclear. It is defined primarily by the facilities and services; however, other factors also need to be taken into consideration, such as social behaviours and perception aspects.

There are also methodological limitations; for example, such studies are very rare in Qatar and many people do not feel comfortable answering questions about their private lives, homes and neighbourhoods, so developing methodology will match the third dimension out of this limitation.

Satisfying residents' needs is not an easy task. Cut parameters are a difficult issue to solve, as the results are subjective, and so trying to identify clear cut factors while considering a full range of users' needs and desires that should be included in the assessment tool is challenging. The concept of user satisfaction with residential quality is determined by various personal, social and cultural factors, which are reflected implicitly in the complex and dynamic relationship between the residents and their living environment. Finally, the assessment tool as developed in this study was found to cover too wide a range of factors and dimensions, which made its use rather complex for following the analysis and findings.

\subsection{Future recommendations developing the QOUL assessment tool}

The main aim of this study was to develop qualitative standards and criteria for an assessment tool for investigating levels of user satisfaction in residential neighbourhoods. The research framework and the assessment tool thus developed may be used to make recommendations for improving neighbourhoods that would suit the real life needs and wants of users and residents. The focus of the study was to adapt quality standards to suit the Doha environment, rather than use Western applications that do not suit local living standards and climate.

Investigation of QOUL is at the core of current theories of contemporary urban design and planning; however, in order to achieve a better quality of life for existing communities, certain priorities must be identified. These must be based on applying investigative studies using appropriate qualitative standards and methodologies to determine users' perceptions and needs; therefore, an integration with quantitative methods will be recommended. The results of such investigations can be used to help provide resident-friendly, sustainable development of new and existing neighbourhoods. Suggestions thus include that researchers in this field develop criteria and assessment measures for every neighbourhood element separately: residential building, services facilities and circulation elements using 
qualitative and quantitative methods. Researchers may also want to explore more urban issues in detail and make a future research and assessment on the relationship between the building height and street width and scale that impact the urban fabric and affect social behaviour and resident use. In addition, future research should focus only on the relationship between the private and public spaces in the neighbourhood to better understand the links between them.

\section{References}

[1] Salama, A. M., Wiedmann, F., Thierstein, A. The Production of Urban Qualities in the Emerging City of Doha: Urban Space Diversity as a Case for Investigating the "Lived Space". International Symposium CAUMME 2012. Istanbul: Yildiz Technical University Printing\& Publishing Center, pp. 311-323, (2012).

[2] Marans, R. W. Understanding environmental quality through quality of life studies: the 2001 DAS and its use of subjective and objective indicators. Landscape and Urban Planning, Volume 65 (Issue 1-2), pp 73-83, 2003.

[3] Marans, R. W., \& Stimson, R. An Overview of Quality of Urban Life. In Investigating Quality of Urban life. Melbourne: Springer Science and Business, 28, pp. 1, 2011.

[4] Kamp, I. V., Leidelmeijer, K., Marsman, G., \& de Hollander, A. Urban environmental quality and human well-being Towards a conceptual framework and demarcation of concepts; a literature study. Volume 65 (Issue 1-2) 14, pp. 7, 2003.

[5] Hester, R. (1984). Social Factors in Site Planning: The state of Arts. In Planning Neighborhood Space with People, New York: Van Nostrand Reinhold Company, pp. 27-55, 1984.

[6] Aiello, A., Ardone, R. G., \& Scopelliti, M. Neighborhood planning improvement: Physical attributes, cognitive and affective evaluation and activities in two neighborhoods in Rome. Evaluation and Program Planning, 33(3), pp. 265-275, 2010.

[7] Amerigo, M., \& Juan, A. I. A Theoretical and Methodological Approach to The Study of Residential Satisfaction. Journal of Environmental Psychology, pp. 48-57, 1997.

[8] Lynch, K. (2010). The Image of the Environment and the City Image and its Elements. In M. Larice, \& E. Macdonald, The Urban Design Reader. New York: Routledge, 153-166, p. 158, 2010.

[9] Moustafa, Y. M. (2009, March). Design and neighborhood sense of community: an integrative and cross-culturally valid theoretical framework. Archnet-IJAR, International Journal of Architectural Research, vol. 3 (Issue 1), pp. 71-91, 2009.

[10] Oktay, D., \& Marans, R. W. Overall Quality of Urban Life Neighborhood Satisfaction: A Household Survey in the Walled City of Famagusta. CSBElAPS, Istanbul: Open House International, pp. 27-36, 2010.

[11] Smith, T., Nelischer, M., \& Perkins, N. Quality of an urban community: a framework for understanding the relationship between quality and physical 
402 The Sustainable City IX, Vol. 1

form. Landscape and Urban Planning, Volume 39 (Issues 2-3), pp. 292-241, 1997.

[12] Richman, A. Planning Residential Environments: The Social Performance Standard. Journal of the American Planning Association, 45(4), pp. 448-458, 2007.

[13] Carmona, M., Tiesdell, S., Heath, T., \& OC, T. Public Places - Open Spaces The Dimensions of Urban Design. Elsevier, 106-124, pp. 109, 2010. 